\title{
Modified Ratio Estimators for Population Mean Using Function of Quartiles of Auxiliary Variable
}

\author{
J. Subramani and G. Kumarapandiyan
}

\begin{abstract}
The present paper deals with some new modified ratio estimators for estimation of population mean using the quartiles and its functions of the auxiliary variable. The bias and the mean squared error of the proposed estimators are obtained and are compared with some of the existing modified ratio estimators. As a result, we have observed that the proposed modified ratio estimators perform better than the existing modified ratio estimators. These are explained with the help of numerical examples.
\end{abstract}

Keywords--- Bias, Mean Squared Error, Inter-Quartile Range, Simple Random Sampling

\section{INTRODUCTION}

$\mathrm{T}$ HE aim of sampling is to obtain fairly precise results about population parameters of the study variable $\mathrm{Y}$ on the basis of random samples. The simplest estimator of population parameter is based on simple random sampling when there is no additional information is available. In sampling theory it is usual to make use of information on auxiliary variables to obtain more efficient estimators. Some of the estimation procedures in sampling theory exploit the use of correlation between the variables $\mathrm{Y}$ and $\mathrm{X}$ for the purpose of enhancing the precision of the estimators where the information on the auxiliary variable $\mathrm{X}$ is known.. It is well known that when the auxiliary information is available, the ratio, product and regression estimators are widely utilized in many situations. Theoretically, it has been established that, in general, the regression estimator is more efficient than the ratio and product estimators except when the regression line of the character under study on the auxiliary character passes through the neighbourhood of the origin. In this case the efficiency of the estimators is almost equal.

However, due to the stronger intuitive appeal, statisticians are more inclined towards the use of ratio and product estimators. Perhaps that is why an extensive work has been done in the direction of improving the performance of these estimators. For ratio estimators in sampling theory, population information of the auxiliary variable, such as the coefficient of variation or the kurtosis, is often used to increase the efficiency of the estimation for a population mean. In the past, a number of estimators including modified ratio estimators are suggested with known Co-efficient of Variation, Co-efficient of Kurtosis, Co-efficient of Skewness, Population Correlation Coefficient etc. However there is no attempt is made to use the known

J. Subramani, Associate Professor, Department of Statistics, Pondicherry University, Puducherry, India. E-mail: drjsubramani@yahoo.co.in

G. Kumarapandiyan, Research Scholar, Department of Statistics Pondicherry University, Puducherry, India. E-mail: kumarstat88@gmail.com value of the population quartiles and their functions of the auxiliary variable to improve the ratio estimators. Further we know that the value of quartiles and their functions are unaffected and robustness by the extreme values or the presence of outliers in the population values unlike the other parameters like the mean, coefficient of variation, coefficient of skewness and coefficient of kurtosis etc. These points discussed above have motivated us to introduce a modified ratio estimator using the known value of the population quartiles and their functions of the auxiliary variable. There are three quartiles called, first quartile, second quartile and third quartile. The second quartile is equal to the median. The first quartile is also called lower quartile and is denoted by $Q_{1}$. The third quartile is also called upper quartile and is denoted by $Q_{3}$. The lower quartile is a point which has $25 \%$ observations less than it and $75 \%$ observations are above it. The upper quartile is a point with $75 \%$ observations less than it and 25\% observations are above it.

The inter-quartile range is another range used as a measure of the spread. The difference between upper and lower quartiles $\left(Q_{3}-Q_{1}\right)$, which is called the inter-quartile range, also indicates the dispersion of a data set. The inter-quartile range spans $50 \%$ of a data set, and eliminates the influence of outliers because, in effect, the highest and lowest quarters are removed. The formula for inter-quartile range is:

$$
Q_{r}=\left(Q_{3}-Q_{1}\right)
$$

The semi-quartile range is another measure of spread. It is calculated as one half of the difference between the $Q_{3}$ and $Q_{1}$. The formula for semi-quartile range is:

$$
Q_{d}=\left(Q_{3}-Q_{1}\right) / 2
$$

Since half the values in a distribution lie between $Q_{3}$ and $Q_{1}$, the semi-quartile range is one-half the distance needed to cover half the values. In a symmetric distribution, an interval stretching from one semi-quartile range below the median to one semi-quartile above the median will contain one-half of the values. The semi-quartile range is hardly affected by higher values, so it is a good measure of spread to use for skewed distributions. Another measure has been suggested in this paper and named as Quartile average and takes the notation $Q_{a}$ which is defined as

$$
Q_{\mathrm{a}}=\left(\mathrm{Q}_{3}+\mathrm{Q}_{1}\right) / 2
$$

The Ratio estimator for the population mean $\bar{Y}$ of the study variable $\mathrm{Y}$ is defined as

$$
\widehat{\mathrm{Y}}_{\mathrm{R}}=\frac{\overline{\mathrm{y}}}{\overline{\mathrm{x}}} \overline{\mathrm{X}}=\widehat{\mathrm{R}} \overline{\mathrm{X}} \text {, where } \widehat{\mathrm{R}}=\frac{\overline{\mathrm{y}}}{\overline{\mathrm{x}}}=\frac{\mathrm{y}}{\mathrm{x}}
$$


where $\widehat{R}$ is the estimate of $R=\frac{\bar{Y}}{\bar{X}}=\frac{Y}{X}, \bar{y}$ is the sample mean of the study variable Yand $\overline{\mathrm{x}}$ is the sample mean of auxiliary variable $\mathrm{X}$. It is assumed that the population mean $\overline{\mathrm{X}}$ of auxiliary variable $\mathrm{X}$ is known.

Many modified ratio type estimators available in the literature are biased but have minimum mean squared errors compared to that of usual ratio estimator. Some of the modified ratio estimators, which are to be compared with that of the proposed estimators, are listed below.

Sisodia and Dwivedi [2] has suggested a modified ratio estimator using the population coefficient of variation $C_{x}$ of auxiliary variable $X$ for estimating $\bar{Y}$ together with its bias and mean squared error and are as given below:

$\widehat{\bar{Y}}_{1}=\bar{y}\left[\frac{\bar{X}+C_{x}}{\bar{x}+C_{x}}\right]$

$\mathrm{B}\left(\widehat{\mathrm{Y}}_{1}\right)=\frac{(1-\mathrm{f})}{\mathrm{n}} \overline{\mathrm{Y}}\left(\theta_{1}^{2} \mathrm{C}_{\mathrm{x}}^{2}-\theta_{1} \mathrm{C}_{\mathrm{x}} \mathrm{C}_{\mathrm{y}} \rho\right)$

$\operatorname{MSE}\left(\widehat{\bar{Y}}_{1}\right)=\frac{(1-f)}{n} \bar{Y}^{2}\left(C_{y}^{2}+\theta_{1}^{2} C_{x}^{2}-2 \theta_{1} C_{x} C_{y} \rho\right)$

where $f=\frac{n}{N}$ and $\theta_{1}=\frac{\bar{x}}{\bar{X}+C_{x}}$

When the coefficient of kurtosis of auxiliary variable $\mathrm{X}$ is known, Singh et.al [3] has developed a modified ratio type estimator for estimating $\bar{Y}$ and derived its bias and mean squared error as given below:

$\widehat{\mathrm{Y}}_{2}=\overline{\mathrm{y}}\left[\frac{\overline{\mathrm{X}}+\beta_{2}}{\overline{\mathrm{x}}+\beta_{2}}\right]$

$\mathrm{B}\left(\widehat{\mathrm{Y}}_{2}\right)=\frac{(1-\mathrm{f})}{\mathrm{n}} \overline{\mathrm{Y}}\left(\theta_{2}^{2} \mathrm{C}_{\mathrm{x}}^{2}-\theta_{2} \mathrm{C}_{\mathrm{x}} \mathrm{C}_{\mathrm{y}} \rho\right)$

$\operatorname{MSE}\left(\widehat{\bar{Y}}_{2}\right)=\frac{(1-f)}{n} \bar{Y}^{2}\left(C_{y}^{2}+\theta_{2}^{2} C_{x}^{2}-2 \theta_{2} C_{x} C_{y} \rho\right)$

where $f=\frac{n}{N}$ and $\theta_{2}=\frac{\bar{x}}{\bar{X}+\beta_{2}}$

Motivated by Singh et.al [3], Yan and Tian [5] has suggested another modified ratio estimator using the coefficient of skewness of the auxiliary variable $X$ together with its bias and mean squared error and are as given below:

$\widehat{\mathrm{Y}}_{3}=\overline{\mathrm{y}}\left[\frac{\overline{\mathrm{X}}+\beta_{1}}{\overline{\mathrm{x}}+\beta_{1}}\right]$

$$
\begin{aligned}
& \mathrm{B}\left(\widehat{\mathrm{Y}}_{3}\right)=\frac{(1-\mathrm{f})}{\mathrm{n}} \overline{\mathrm{Y}}\left(\theta_{3}^{2} \mathrm{C}_{\mathrm{x}}^{2}-\theta_{3} \mathrm{C}_{\mathrm{x}} \mathrm{C}_{\mathrm{y}} \rho\right) \\
& \operatorname{MSE}\left(\widehat{\mathrm{Y}}_{3}\right)=\frac{(1-\mathrm{f})}{\mathrm{n}} \overline{\mathrm{Y}}^{2}\left(\mathrm{C}_{\mathrm{y}}^{2}+\theta_{3}^{2} \mathrm{C}_{\mathrm{x}}^{2}-2 \theta_{3} \mathrm{C}_{\mathrm{x}} \mathrm{C}_{\mathrm{y}} \rho\right) \\
& \text { where } \mathrm{f}=\frac{\mathrm{n}}{\mathrm{N}} \text { and } \theta_{3}=\frac{\overline{\mathrm{x}}}{\overline{\mathrm{X}}+\beta_{1}}
\end{aligned}
$$

When the population correlation coefficient between $\mathrm{X}$ and $\mathrm{Y}$ is known, Singh and Tailor [4] proposed another estimator for estimating $\bar{Y}$ together with its bias and mean squared error and are as given below:

$$
\begin{aligned}
& \widehat{\mathrm{Y}}_{4}=\overline{\mathrm{y}}\left[\frac{\overline{\mathrm{X}}+\rho}{\overline{\mathrm{X}}+\rho}\right] \\
& \mathrm{B}\left(\widehat{\mathrm{Y}}_{4}\right)=\frac{(1-f)}{\mathrm{n}} \overline{\mathrm{Y}}\left(\theta_{4}^{2} C_{x}^{2}-\theta_{4} C_{x} C_{y} \rho\right) \\
& \operatorname{MSE}\left(\widehat{\mathrm{Y}}_{4}\right)=\frac{(1-f)}{\mathrm{n}} \bar{Y}^{2}\left(C_{y}^{2}+\theta_{4}^{2} C_{x}^{2}-2 \theta_{4} C_{x} C_{y} \rho\right) \\
& \text { where } f=\frac{n}{N} \text { and } \theta_{4}=\frac{\bar{X}}{\bar{X}+\rho}
\end{aligned}
$$

\section{PRoposed Modified Ratio Estimators}

The proposed modified ratio estimators for population mean $\bar{Y}$ are

$\widehat{\bar{Y}}_{\mathrm{p} 1}=\bar{y}\left[\frac{\overline{\mathrm{x}}+\mathrm{Q}_{3}}{\overline{\mathrm{x}}+\mathrm{Q}_{3}}\right]$
$\widehat{\overline{\mathrm{Y}}}_{\mathrm{p} 2}=\overline{\mathrm{y}}\left[\frac{\overline{\mathrm{X}}+\mathrm{Q}_{\mathrm{r}}}{\overline{\mathrm{x}}+\mathrm{Q}_{\mathrm{r}}}\right]$
$\widehat{\overline{\mathrm{Y}}}_{\mathrm{p} 3}=\overline{\mathrm{y}}\left[\frac{\overline{\mathrm{X}}+\mathrm{Q}_{\mathrm{d}}}{\overline{\mathrm{x}}+\mathrm{Q}_{\mathrm{d}}}\right]$
$\widehat{\overline{\mathrm{Y}}}_{\mathrm{p} 4}=\overline{\mathrm{y}}\left[\frac{\overline{\mathrm{X}}+\mathrm{Q}_{\mathrm{a}}}{\overline{\mathrm{x}}+\mathrm{Q}_{\mathrm{a}}}\right]$

To the first degree of approximation, the biases and mean squared errors of $\widehat{Y}_{p j}$ are given below:

$$
\begin{aligned}
\mathrm{B}\left(\widehat{\overline{\mathrm{Y}}}_{\mathrm{pj}}\right)=\frac{(1-\mathrm{f})}{\mathrm{n}} \overline{\mathrm{Y}}\left(\theta_{\mathrm{pi}}^{2} \mathrm{C}_{\mathrm{x}}^{2}-\theta_{\mathrm{pi}} \mathrm{C}_{\mathrm{x}} \mathrm{C}_{\mathrm{y}} \rho\right) ; \\
\mathrm{j}=1,2,3 \text { and } 4 \\
\operatorname{MSE}\left(\widehat{\mathrm{Y}}_{\mathrm{pj}}\right)=\frac{(1-\mathrm{f})}{\mathrm{n}} \overline{\mathrm{Y}}^{2}\left(\mathrm{C}_{\mathrm{y}}^{2}+\theta_{\mathrm{pi}}^{2} \mathrm{C}_{\mathrm{x}}^{2}-2 \theta_{\mathrm{pi}} \mathrm{C}_{\mathrm{x}} \mathrm{C}_{\mathrm{y}} \rho\right) ; \\
\mathrm{j}=1,2,3 \text { and } 4
\end{aligned}
$$

where $\mathrm{f}=\frac{\mathrm{n}}{\mathrm{N}}, \theta_{\mathrm{p} 1}=\frac{\overline{\mathrm{x}}}{\overline{\mathrm{X}}+\mathrm{Q}_{3}}, \theta_{\mathrm{p} 2}=\frac{\overline{\mathrm{x}}}{\overline{\mathrm{X}}+\mathrm{Q}_{\mathrm{r}}}$,

$\theta_{p 3}=\frac{\bar{X}}{\bar{X}+Q_{d}}$ and $\theta_{p 4}=\frac{\bar{X}}{\bar{X}+Q_{a}}$

\section{COMPARISON OF PROPOSED ESTIMATORS WITH THE EXISTING ESTIMATORS}

To the first order degree of approximation, the mean squared error of the modified ratio estimators listed from (1.2) to (1.5) are given below:

$$
\begin{aligned}
& B\left(\widehat{\bar{Y}}_{1}\right)=\frac{(1-f)}{n} \bar{Y}\left(\theta_{1}^{2} C_{x}^{2}-\theta_{1} C_{x} C_{y} \rho\right) \\
& \operatorname{MSE}\left(\widehat{\mathrm{Y}}_{1}\right)=\frac{(1-\mathrm{f})}{\mathrm{n}} \overline{\mathrm{Y}}^{2}\left(\mathrm{C}_{\mathrm{y}}^{2}+\theta_{1}^{2} \mathrm{C}_{\mathrm{x}}^{2}-2 \theta_{1} \mathrm{C}_{\mathrm{x}} \mathrm{C}_{\mathrm{y}} \rho\right. \\
& \mathrm{B}\left(\widehat{\widehat{Y}}_{2}\right)=\frac{(1-f)}{n} \bar{Y}\left(\theta_{2}^{2} C_{x}^{2}-\theta_{2} C_{x} C_{y} \rho\right) \\
& \operatorname{MSE}\left(\widehat{\mathrm{Y}}_{2}\right)=\frac{(1-\mathrm{f})}{\mathrm{n}} \overline{\mathrm{Y}}^{2}\left(\mathrm{C}_{\mathrm{y}}^{2}+\theta_{2}^{2} \mathrm{C}_{\mathrm{x}}^{2}-2 \theta_{2} \mathrm{C}_{\mathrm{x}} \mathrm{C}_{\mathrm{y}} \rho\right) \\
& B\left(\widehat{\mathrm{Y}}_{3}\right)=\frac{(1-f)}{n} \bar{Y}\left(\theta_{3}^{2} C_{x}^{2}-\theta_{3} C_{x} C_{y} \rho\right) \\
& \operatorname{MSE}\left(\widehat{\mathrm{Y}}_{3}\right)=\frac{(1-f)}{n} \bar{Y}^{2}\left(C_{y}^{2}+\theta_{3}^{2} C_{x}^{2}-2 \theta_{3} C_{x} C_{y} \rho\right)
\end{aligned}
$$


$B\left(\widehat{\bar{Y}}_{4}\right)=\frac{(1-f)}{n} \bar{Y}\left(\theta_{4}^{2} C_{x}^{2}-\theta_{4} C_{x} C_{y} \rho\right)$

$\operatorname{MSE}\left(\widehat{\mathrm{Y}}_{4}\right)=\frac{(1-\mathrm{f})}{\mathrm{n}} \overline{\mathrm{Y}}^{2}\left(\mathrm{C}_{\mathrm{y}}^{2}+\theta_{4}^{2} \mathrm{C}_{\mathrm{x}}^{2}-2 \theta_{4} \mathrm{C}_{\mathrm{x}} \mathrm{C}_{\mathrm{y}} \rho\right)$

For the convenience of the readers, biases and mean squared errors discussed above are represented in a single class as given below:

$$
\begin{aligned}
& B\left(\widehat{\bar{Y}}_{j}\right)=\frac{(1-f)}{n} \bar{Y}\left(\theta_{i}^{2} C_{x}^{2}-\theta_{i} C_{x} C_{y} \rho\right) ; i=1,2.3,4 \\
& \operatorname{MSE}\left(\widehat{\bar{Y}}_{i}\right)=\frac{(1-f)}{n} \bar{Y}^{2}\left(C_{y}^{2}+\theta_{i}^{2} C_{x}^{2}-2 \theta_{i} C_{x} C_{y} \rho\right) ;
\end{aligned}
$$

$\mathrm{i}=1,2,3,4$

where $\mathrm{f}=\frac{\mathrm{n}}{\mathrm{N}}, \theta_{1}=\frac{\overline{\mathrm{x}}}{\overline{\mathrm{X}}+\mathrm{C}_{\mathrm{x}}}, \theta_{2}=\frac{\overline{\mathrm{X}}}{\overline{\mathrm{X}}+\beta_{2}}, \theta_{3}=\frac{\overline{\mathrm{x}}}{\overline{\mathrm{X}}+\beta_{1}}$ and $\theta_{4}=\frac{\overline{\mathrm{X}}}{\overline{\mathrm{X}}+\rho}$

Bias and mean squared error of the proposed modified ratio type estimators to the first degree of approximation are given below:

$B\left(\widehat{\bar{Y}}_{p j}\right)=\frac{(1-f)}{{ }_{n}} \bar{Y}\left(\theta_{p j}^{2} C_{x}^{2}-\theta_{p j} C_{x} C_{y} \rho\right) ;$
$j=1,2,3,4$

$\operatorname{MSE}\left(\widehat{\bar{Y}}_{\mathrm{pj}}\right)=\frac{(1-\mathrm{f})}{\mathrm{n}} \overline{\mathrm{Y}}^{2}\left(\mathrm{C}_{\mathrm{y}}^{2}+\theta_{\mathrm{pj}}^{2} \mathrm{C}_{\mathrm{x}}^{2}-2 \theta_{\mathrm{pj}} \mathrm{C}_{\mathrm{x}} \mathrm{C}_{\mathrm{y}} \rho\right) ;$

$$
j=1,2,3,4
$$

where $\mathrm{f}=\frac{\mathrm{n}}{\mathrm{N}}, \theta_{\mathrm{p} 1}=\frac{\overline{\mathrm{X}}}{\overline{\mathrm{X}}+\mathrm{Q}_{3}}, \theta_{\mathrm{p} 2}=\frac{\overline{\mathrm{X}}}{\overline{\mathrm{X}}+\mathrm{Q}_{\mathrm{r}}}$,

$\theta_{\mathrm{p} 3}=\frac{\overline{\mathrm{X}}}{\overline{\mathrm{X}}+\mathrm{Q}_{\mathrm{d}}}$ and $\theta_{\mathrm{p} 4}=\frac{\overline{\mathrm{X}}}{\overline{\mathrm{X}}+\mathrm{Q}_{\mathrm{a}}}$

From (12) and (14), it is observed that proposed estimators $\widehat{\mathrm{Y}}_{\mathrm{p}} ; \mathrm{i}=1,2,3$ and 4 are more efficient than the existing modified ratio estimators $\widehat{\bar{Y}}_{i} ; i=1,2,3$ and 4

$$
\begin{aligned}
& \operatorname{MSE}\left(\widehat{\bar{Y}}_{p j}\right)<\operatorname{MSE}\left(\widehat{\bar{Y}}_{i}\right) \text { if } \rho<\frac{\left(\theta_{p j}+\theta_{i}\right)}{2} \frac{C_{x}}{C_{y}} \\
& ; i=1,2,3,4 ; j=1,2,3,4
\end{aligned}
$$

\section{EMPIRICAL STUDY}

The performances of the proposed estimators are assessed with that of the modified ratio estimators for two populations. The populations 1 and 2 are taken from Murthy [1] given in page 228. The population constants computed from the above data are given below:

Population-1: Murthy [1]

$\mathrm{X}=$ Fixed Capital and $\mathrm{Y}=$ Output for 80 factories in a region

$$
\begin{array}{llll}
\mathrm{N}=80 & \mathrm{n}=20 & \overline{\mathrm{Y}}=51.8264 & \overline{\mathrm{X}}=11.2646 \\
\rho=0.9413 & \mathrm{~S}_{\mathrm{y}}=18.3569 & \mathrm{C}_{\mathrm{y}}=0.3542 & \mathrm{~S}_{\mathrm{x}}=8.4563 \\
\mathrm{C}_{\mathrm{x}}=0.7507 & \beta_{2}=-0.06339 & \beta_{1}=1.05 & \mathrm{Q}_{3}=16.975 \\
\mathrm{Q}_{\mathrm{r}}=11.825 & \mathrm{Q}_{\mathrm{d}}=5.9125 & \mathrm{Q}_{\mathrm{a}}=11.0625 &
\end{array}
$$

Population-2: Murthy [1]

$\mathrm{X}=$ Data on number of workers and $\mathrm{Y}=$ Output for 80 factories in a region

$$
\begin{array}{llll}
\mathrm{N}=80 & \mathrm{n}=20 & \overline{\mathrm{Y}}=51.8264 & \overline{\mathrm{X}}=2.8513 \\
\rho=0.9150 & \mathrm{~S}_{\mathrm{y}}=18.3569 & \mathrm{C}_{\mathrm{y}}=0.3542 & \mathrm{~S}_{\mathrm{x}}=2.7042 \\
\mathrm{C}_{\mathrm{x}}=0.9484 & \beta_{2}=1.3005 & \beta_{1}=0.6978 & \mathrm{Q}_{3}=4.475 \\
\mathrm{Q}_{\mathrm{r}}=3.615 & \mathrm{Q}_{\mathrm{d}}=1.8075 & \mathrm{Q}_{\mathrm{a}}=2.6675 &
\end{array}
$$

The biases of the existing and proposed modified ratio type estimators are given in the following table:

Table 1: Biases of the Existing and Proposed Estimators

\begin{tabular}{|c|c|c|c|}
\hline \multicolumn{2}{|c|}{ Estimators } & Population1 & Population2 \\
\hline \multirow{4}{*}{ Existing } & $\hat{Y}_{1}$ & 0.5066 & 0.5360 \\
\cline { 2 - 4 } & $\hat{\bar{Y}}_{2}$ & 0.6184 & 0.4142 \\
\cline { 2 - 4 } & $\hat{Y}_{3}$ & 0.4714 & 0.6483 \\
\cline { 2 - 4 } & $\hat{Y}_{4}$ & 0.4839 & 0.5496 \\
\hline \multirow{4}{*}{ Proposed } & $\hat{Y}_{1}$ & 0.0198 & 0.0323 \\
\cline { 2 - 4 } & $\hat{\bar{Y}}_{22}$ & 0.0234 & 0.0765 \\
\cline { 2 - 4 } & $\hat{\hat{Y}}_{33}$ & 0.1520 & 0.2892 \\
\cline { 2 - 4 } & $\hat{Y}_{p 4}$ & 0.0333 & 0.1579 \\
\hline
\end{tabular}

The mean squared errors of the existing and proposed modified ratio type estimators with are given in the following table:

Table 2: Mean Squared Errors of the Existing and Proposed Estimators

\begin{tabular}{|c|c|c|c|}
\hline \multicolumn{2}{|c|}{ Estimators } & Population1 & Population2 \\
\hline \multirow{4}{*}{ Existing } & $\hat{\bar{Y}}_{1}$ & 15.2581 & 17.1881 \\
\cline { 2 - 4 } & $\hat{\bar{Y}}_{2}$ & 19.3382 & 12.8425 \\
\cline { 2 - 4 } & $\hat{\bar{Y}}_{3}$ & 14.0112 & 21.3660 \\
\cline { 2 - 4 } & $\hat{\bar{Y}}_{4}$ & 14.4502 & 17.6849 \\
\hline \multirow{4}{*}{ Proposed } & $\hat{\bar{Y}}_{p 1}$ & 1.5562 & 2.2604 \\
\cline { 2 - 4 } & $\hat{\bar{Y}}_{p 2}$ & 1.5486 & 2.9489 \\
\cline { 2 - 4 } & $\hat{\bar{Y}}_{p 3}$ & 3.9830 & 8.6761 \\
\cline { 2 - 4 } & $\hat{\bar{Y}}_{p 4}$ & 1.6470 & 4.8281 \\
\hline
\end{tabular}

The biases and mean squared errors of existing and proposed modified ratio estimators are summarized and given in the following table:

Table 3: Comparison of Existing and Proposed Estimators with their Biases and Mean Squared Errors

\begin{tabular}{|c|c|c|c|c|c|}
\hline \multicolumn{2}{|c|}{ Estimators } & \multicolumn{2}{c|}{ Population 1 } & \multicolumn{2}{c|}{ Population 2 } \\
\cline { 2 - 6 } & Bias & MSE & Bias & MSE \\
\hline \multirow{4}{*}{ Existing } & $\hat{\bar{Y}}_{1}$ & 0.5066 & 15.2581 & 0.5360 & 17.1881 \\
\cline { 2 - 6 } & $\hat{\bar{Y}}_{2}$ & 0.6184 & 19.3382 & 0.4142 & 12.8425 \\
\cline { 2 - 6 } & $\hat{\bar{Y}}_{3}$ & 0.4714 & 14.0112 & 0.6483 & 21.3660 \\
\cline { 2 - 6 } & $\hat{\bar{Y}}_{4}$ & 0.4839 & 14.4502 & 0.5496 & 17.6849 \\
\hline \multirow{4}{*}{ Proposed } & $\hat{\bar{Y}}_{p 1}$ & 0.0198 & 1.5562 & 0.0323 & 2.2604 \\
\cline { 2 - 6 } & $\hat{\bar{Y}}_{p 2}$ & 0.0234 & 1.5486 & 0.0765 & 2.9489 \\
\cline { 2 - 6 } & $\hat{\bar{Y}}_{p 3}$ & 0.1520 & 3.9830 & 0.2892 & 8.6761 \\
\cline { 2 - 6 } & $\hat{\bar{Y}}_{p 4}$ & 0.0333 & 1.6470 & 0.1579 & 4.8281 \\
\hline
\end{tabular}




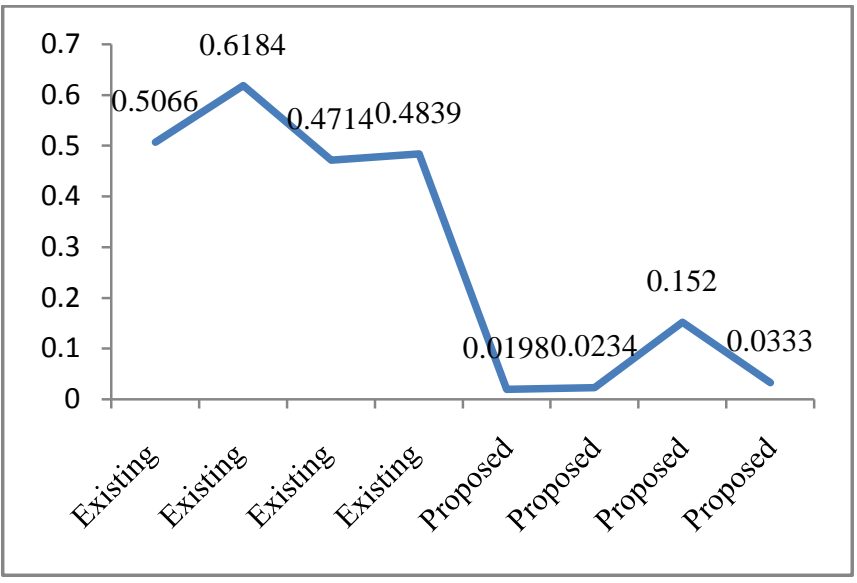

Figure 1: Biases of the Existing and Proposed Estimators for Population 1

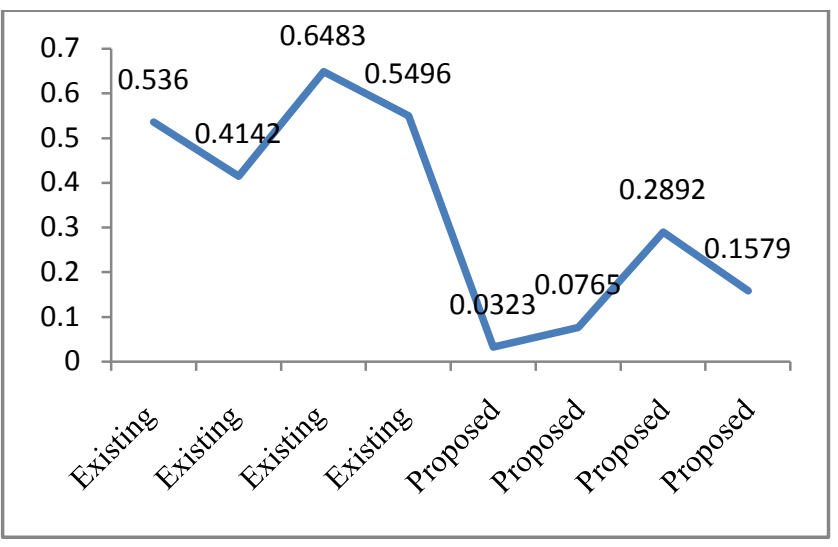

Figure 2: Biases of the Existing and Proposed Estimators for Population 2

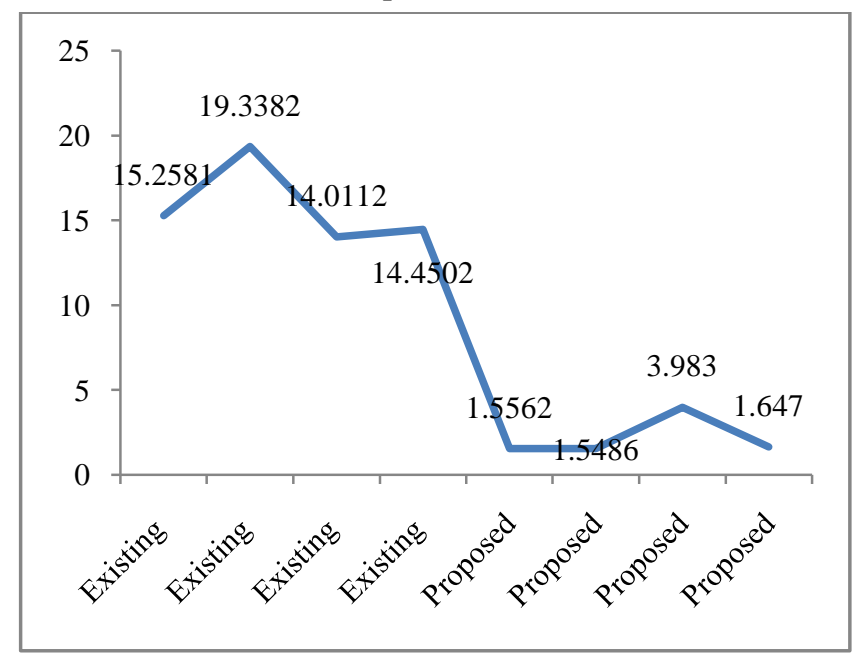

Figure 3: Mean Squared Errors of the Existing and Proposed Estimators for Population 1

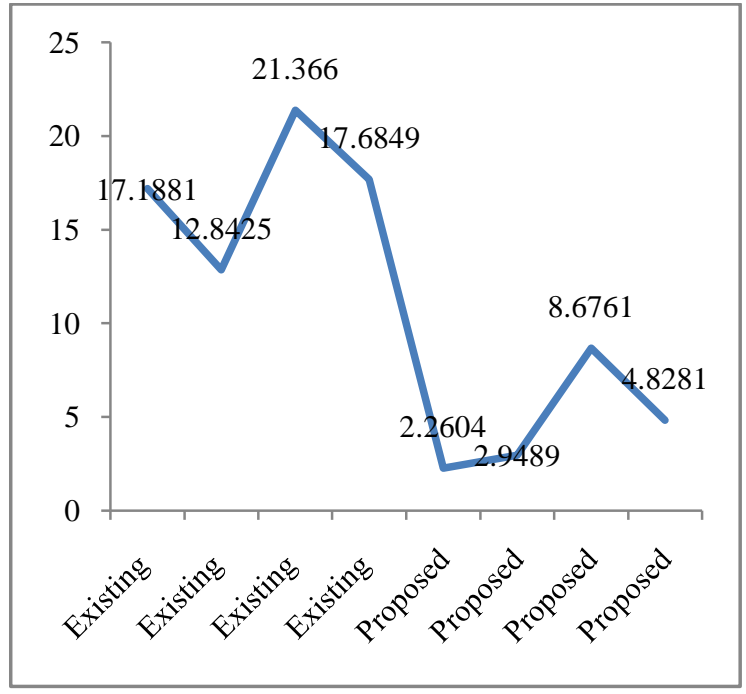

Figure 4: Mean Squared Errors of the Existing and Proposed Estimators for Population 2

\section{CONCLUSION}

In this paper we have proposed modified ratio estimators using known values of population quartiles of auxiliary variable and their function. The biases and mean squared errors of the proposed estimators are obtained and compared with that of existing modified ratio estimators. Further we have derived the conditions for which the proposed estimators are more efficient than the existing modified ratio estimators. We have also assessed the performances of the proposed estimators for some known populations. It is observed that the biases and mean squared errors of the proposed estimators are less than the biases and mean squared errors of the existing modified ratio estimators for certain known populations.

\section{ACKNOWLEDGEMENT}

The second author wishes to record his gratitude and thanks to the Vice Chancellor, Pondicherry University and other University authorities for having given the financial assistance to carry out this research work through the University Fellowship.

\section{REFERENCES}

[1] M.N. Murthy, "Sampling theory and methods", Statistical Publishing Society, Calcutta, India, 1967.

[2] B.V.S. Sisodia and V.K. Dwivedi, "A modified ratio estimator using coefficient of variation of auxiliary variable", Jour. Ind. Soc. Agri. Stat., Vol. 33(1), Pp. 13-18, 1981.

[3] H.P. Singh, R. Tailor, R. Tailor and M.S. Kakran, "An Improved Estimator of population mean using Power transformation", Journal of the Indian Society of Agricultural Statistics, Vol. 58(2), Pp. 223-230, 2004.

[4] H.P. Singh and R. Tailor, "Use of known correlation coefficient in estimating the finite population means", Statistics in Transition, Vol. 6 (4), Pp. 555-560, 2003.

[5] Z. Yan and B. Tian, "Ratio Method to the Mean Estimation Using Coefficient of Skewness of Auxiliary Variable", ICICA 2010, Part II, CCIS 106, Pp. 103-110, 2010. 


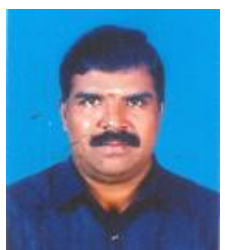

Dr. J. Subramani has received the doctorate degree in Statistics from University of Madras. He is currently working as Associate Professor, Department of Statistics, Pondicherry University. He has more than 25 years of experience both in Teaching and Research. To his academic credit he has received U.S.Nair Young Statistician Award from Indian Society of Probability and Statistics and also the International Young Statistician Award from the International Statistical Institute, The Netherlands. His research interests are Estimation of Variance Components, Missing Data Analysis, Sampling Theory, Incomplete Block Designs, Control Charts and Process Capability Analysis. He has published more than 75 research papers in reputed International and National Journals. He has also participated in many conferences and workshops in India as well as abroad and presented research papers; delivered invited talks and special addresses. He has organized many International and National Conferences and also acted as an organizing committee member in many conferences.

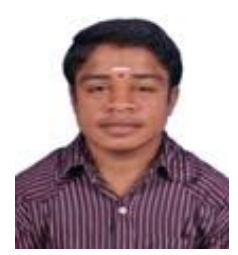

G.Kumarapandiyan did his M.Sc. Statistics with First class distinction at Department of Statistics, Ramanujan School of Mathematical Sciences, Pondicherry University, R.V. Nagar, Kalapet, Puducherry-605 014 during 2009-2011. He is presently pursuing his Ph.D. in Statistics in the area of Sampling Theory under the guidance of Dr. J. Subramani, Associate Professor, Department of Statistics, Pondicherry University, Puducherry. He has been awarded the "Pondicherry University Gold medal" for best performance in B.Sc. Statistics, "Shri Shankar Dayal Sharma Gold Medal" for the best performance in M.Sc. Statistics and also the "Vijaya Bank Gold Medal" for the Best PG Student of Pondicherry University. 